\title{
A VIDA SOB A PANDEMIA: VIVENDO E APRENDENDO A JOGAR; NEM SEMPRE GANHANDO*
}

Afrânio Mendes Catani

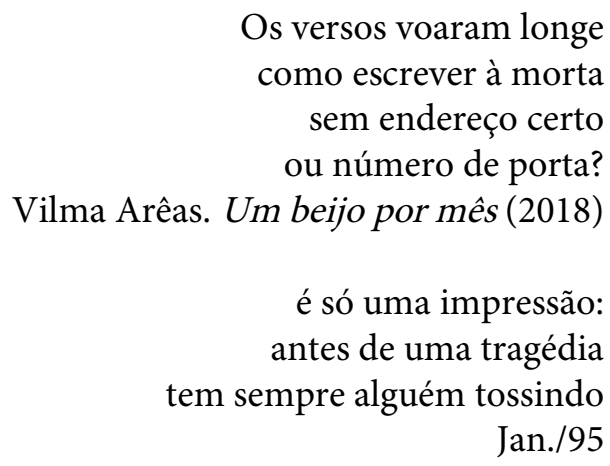

Sérgio Muniz. En San Antonio y São Paulo... (1997)

Dia 13 de março de 2020, sexta-feira, iniciei meu isolamento social, com receio de que a pandemia do coronavírus me carregasse para o beleléu - ainda não tenho plena certeza de que para lá não vou... Encontro-me no grupo de risco em razão de minha idade. Além disso, depois que me separei, moro com mamãe, que completará 99 anos em setembro próximo. Um dia antes, exatamente em 12 de março, almocei com pessoa das mais interessantes e, no dia seguinte, internação doméstica! Grande frustração... Depois, encontros virtuais, conversas telefônicas que duram horas e horas, e-mails, whatsapps etc. Enquanto isso, escrevo esse texto, estando há mais de 80 dias em uma geografia residencial limitada.

Passo, a partir de agora, a falar sobre minha vida sob a pandemia, sobre o que o que estou enfrentando, por onde caminha o meu pensamento.

*DOI - 10.29388/978-65-86678-07-9-0-f.35-52 
Os bares precisam reabrir pra gente beber menos. WhatsApp recebido em 25/04/2020

O sol nas bancas de revista Me enche de alegria e preguiça Quem lê tanta notícia? Caetano Veloso, "Alegria, Alegria”

Tudo bem que vai ter problema. Vai ter. Quem é idoso e está com problema ou deficiência. Mas não é isso tudo que dizem. Acho que na China já está praticamente acabando. Jair Bolsonaro, presidente, sobre a pandemia de Covid-19, no dia 16 de março de 2020, quando morreu a primeira vítima da doença no país; a morte foi confirmada no dia seguinte.

Partindo da epígrafe que acaba de ser citada, extraída da canção de Caetano Veloso, a pergunta continua válida: "Quem lê tanta notícia?”. Bem, eu leio, ao menos em parte. Começo pela Folha de $S$. Paulo (FSP) diariamente, no formato papel, além de passar os olhos em outros informativos que um amigo me envia pelo WhatsApp ( $O$ Estado de S. Paulo, O Globo, Valor Econômico, Carta Capital, Público, Le Monde, L'Humanité, The New York Times, The Guardian, La Repubblica, Corriere della Sera, El País). Entretanto, vou trabalhar aqui apenas com a FSP, uma vez que esse órgão de imprensa dá conta de arrimar os argumentos que desenvolverei no presente capítulo.

As notícias angustiam a todos. Comecei fazendo anotações e reunindo matérias, durante cerca de um mês. Agora que estou a escrever, jogo muita coisa fora, pois fazem pouco sentido, superadas que foram pelos acontecimentos. Lembro-me de Montaigne, de pequeno trecho de um de seus ensaios: "O mundo não é mais que um perene movimento. Nele todas as coisas se movem sem cessar" (Montaigne, Livro III, p 2). O dinamismo da pandemia, em especial no Brasil, bem 
como o noticiário a respeito, atropela a tudo e a todos. Tal dinâmica desestrutura nossas certezas, traz novas possibilidades de enfrentamento da realidade e, ao mesmo tempo infunde pânico: sobreviveremos? Se OK, ficaremos com sequelas?

Everton Lopes Batista, na FSP (18/05/2020), detalha que a Covid-19 tem efeitos que vão muito além da infecção no pulmão e que podem deixar sequelas depois da fase aguda por tempo indeterminado. Rosana Richtmann, infectologista do Instituto Emílio Ribas, declarou que "é uma doença multissistêmica. Nenhum órgão vai escapar. Há a ação direta e indireta do vírus, e ainda há os efeitos dos medicamentos, necessários para salvar o paciente”. Os pulmões são os mais prejudicados, mas o parasita pode ser instalar e causar danos a outros órgãos: "O vírus se conecta com as células do corpo através de um receptor específico, o ECA-2. Além do sistema respiratório, células do intestino, rins e vasos sanguíneos possuem os mesmos receptores podem ser infectados pelo parasita"- a matéria detalha os prejuízos que podem ser causados aos olhos, nariz, coração e vasos sanguíneos, fígado, pele, cérebro, rins, intestino.

Professor aposentado na USP, ainda vinculado ao Programa de Pós-Graduação em Educação (PPGE) da Faculdade de Educação, desde setembro de 2019 fui contratado como professor visitante junto ao PPGE da Universidade Federal Fluminense. Dei aulas até dezembro do ano passado e, quando faltavam poucos dias para iniciar o ano letivo de 2020, a pandemia atacou e nada foi adiante. Assim, posso dizer que sou privilegiado: continuo recebendo meus proventos, tendo a liberdade de trabalhar em casa, segundo o meu ritmo, escrevendo, estudando, participando de reuniões virtuais.

Dia $1^{\circ}$ de maio, sexta-feira, feriado. Por volta das $9 \mathrm{~h} 30$ abro a janela da área de serviço do apartamento e vejo um homem uniformizado, com capacete e máscara, provavelmente funcionário que veio fazer manutenção hidráulica, elétrica ou do gás, caminhando pelo corredor. Sorrindo, berra pelo celular: "Olá! Bom feriado para quem estudou!". Colhido de surpresa, me espanto com o bom humor e a dureza 
da frase. Penso como integro parcela ínfima da população brasileira, que possui grande autonomia relativa e só consegue se manter em isolamento social graças ao trabalho que executam pessoas como esse funcionário, correndo o risco de ser contaminado pela Covid-19.

Leio o depoimento do casal Severino (FSP, 17/05/2020) e encontro várias semelhanças em nossos respectivos cotidianos, envolvendo a realização das atividades no interior do apartamento.

Não tenho rotina de trabalho fixa, mas de segunda a sexta acordo por volta das 9h00; às vezes perto das 10 . Estamos apenas mamãe $\mathrm{e}$ eu em casa. Raramente saio e, quando o faço, tenho roupa e sapato especiais, coloco máscara, vou à banca de revistas, pago semanalmente pelo jornal impresso deixado em minha porta, entrego a lista de compras ao armazém daqui da frente e, a cada dez dias, passo na padaria e trago alguns pratos congelados. Mas em boa parte das vezes, telefonemas resolvem o que vem da panificadora e das raras compras da farmácia. Tudo se localiza num raio de até 150 metros. Minha filha caçula fica comigo nos fins de semana a cada 15 dias; não a maltrato com o labor resultante da culinária que desenvolvo com frequência: peço boa comida de restaurantes, sistema delivery, via aplicativos ou pelo telefone. Uma vez por mês ida aos dois bancos com que opero, conferindo extratos, depositando, transferindo, pagando contas que não foram saldadas pelos aplicativos, sacando dinheiro para fazer frente ao salário da cuidadora de dona Maria José (ela está licenciada, recebendo seus proventos integrais), retornando rapidamente.

$\mathrm{Na}$ maioria dos dias, em que não coloco o focinho mascarado fora dos domínios do lar, após me levantar higienizo tudo, dou uma varrida geral na casa, recolho parte de roupas menores e coloco o conjunto na máquina, tomo sol na varanda por poucos minutos, vou ao banho e começo a ver o que se vai comer. Geralmente faço arroz, im proviso um risoto (exagero: tem queijo ralado, sal, pimenta, azeite, sardinha, ervilha, pedaços de carne, tomate, verdura, queijo, aspargos, ovos, palmito), preparo salada, ovos mexidos, omelete e ... não muito mais. Não temos forno por aqui. Lavo toda a louça, uma vez por sema- 
na passo um aspirador antigo, que pesa uns 15 quilos, por todos os cantos da casa e começo a fazer o que gosto: recebo e mando zaps, olho os e-mails, leio jornais (papel e virtual) e, depois do almoço, começo a escrever e as leituras. Isso vai até às 18h30, quando ajudo mamãe a preparar o jantar dela - eu janto depois, leio mais jornais, assisto aos telejornais e, se não desmaio de sono na sala, me arrasto até o leito e leio um pouco de literatura - romances, poesias, biografias. Ah, ia me esquecendo: acompanho lives que me interessam e, com três ou quatro amigxs, falo diariamente ao telefone e trocamos longas mensagens. Bertha, 14, filha querida, recebe duas chamadas minhas, além de beijo presencial diário. Algumas vezes por semana ligo para as duas outras filhas, Bárbara e Júlia, também queridas, além de trocas de mensagens.

Ou seja, como se pode observar, não é lá uma vida muito emocionante. Entretanto, também não é entediante. $\mathrm{O}$ isolamento é meio triste, às vezes questiono o sentido de estar completamente fora de qualquer atividade que não seja virtual, de me abster de participar de possíveis compromissos que poderiam ser prazerosos, de me exercitar ao ar livre etc. Mas...não há outro jeito! É ficar aqui dentro. Há várias matérias e depoimentos que narram pessoas e modos de agir nesse período de quarentena, como por exemplo as de Laura Mattos, sobre educação; Flávia G. Pinho, acerca das dificuldades dos moradores se cansarem da casa em que residem; Walter Porto, falando dos cinemas; Mônica Bergamo, entrevistando a atriz Taís Araújo, isolada com a família; a reportagem sobre a nova rotina de se viver no edifício Copan, em São Paulo; a quarentena de uma colega, Maria Orlanda Pinassi; o tom pícaro de Ruy Castro; a reportagem de Cláudio Leal contendo 19 breves relatos de brasileiros que narram suas rotinas em tempos de confinamento etc.

Talvez sejam exemplares os escritos de Susana Bragatto e seus 77 relatos até 29/05/2020, intitulados genericamente de "Diário de Confinamento"- em 31/05/2020 saiu o relato 'Lições da cólera em tempos de busca por vacina para Covid-19', datado do dia anterior. Cito, por exemplo, o "Diário" de 01/05/2020, em que a autora aborda di- 
mensão que caminha em direção distinta à maioria dos depoimentos que li. Susana afirmou o seguinte:

Desde o começo da quarentena, posso contar nos quatro dedos de uma mão as sessões de vídeo chamadas de que participei. Nesse tempo todo vi zero lives de qualquer coisa. O lockdown me deu mais vontade ainda de me autoconfinar dentro do confinamento. Numa boa. Claro, confraternizo em casa em doses homeopáticas. E mantenho contato com amigos, família. Sou humana, um bicho social. Mas o frenesi súbito dos mil inputs e conversas agendadas e happy hours virtuais me agonia. E faltam desculpas pra driblar um convite de vídeochat. Que que eu vou dizer? Olha, tô em casa o dia inteiro, mas não tô a fim?.

Volta-me a ideia do movimento, mencionada alguns parágrafos antes. Antonio Gramsci (2007, p. 342) disse que prever significa ver o presente e o passado como movimento. As manchetes de jornais passam em alta velocidade, dia após dia, deixando-me atordoado. Não é para menos. Olhem só o que foi sendo notícia:

"Em menos de cinco meses, vírus escreve biografia em 180 países"; "Brasil passa marca de mil mortes por coronavírus registradas em 24 horas"; "Médicos do Rio continuam sem salário em meio a pandemia”; " 2 meses após $1^{a}$ morte por Covid-19, Brasil é cenário de pesadelos"; "Rio restringe circulação em bairros mais aglomerados"; "Para profissionais da saúde no Pacaembu, 'a guerra chegou"”; "Estamos em uma guerra e na guerra você enterra - Entrevista: Arthur Virgílio Neto"; "Quarentena causada pelo vírus bagunça e piora o sono"; "Hospital de luxo é um sonho de consumo diante do colapso da rede pública nacional"; "Governo federal entrega só 6\% dos respiradores"; "Não quero pessoas infectando nosso povo, diz líder dos EUA [Trump]"; "Após pressão de Bolsonaro Ministério da Saúde amplia o uso de cloroquina"; "Entidades médicas vão à Justiça contra uso da droga"; "Litoral de SP tenta conter invasão em feriadão"; "Entrevistadores do Ibope que coletaram testes de Covid-19 se contaminaram"; "Médicos te- 
mem ser pressionados a prescrever a cloroquina"; "Einstein e Sírio Libanês [hospitais] fazem corte de salários"; "Só 47\% dos alunos da rede estadual de SP assistem aula"; "A cada dez dias, coronavírus chega a mais 630 municípios"; "Cerca de 70 milhões têm acesso precário à internet na pandemia"; "Passageiro do avião terá que pedir para ir ao banheiro”; “Não tire sua máscara' substitui o 'aperte o cinto' (Depoimento)"; "Lotado, vôo BH-SP tem desrespeito a regras de distância".

Durante o período da chamada quarentena - que poderá durar, talvez, 120 dias, ou mais - é possível acompanhar, ainda, alguns debates envolvendo a paralisação das atividades escolares em universidades públicas e, também, a polêmica acerca do adiamento ou não do Exame Nacional do Ensino Médio (ENEM), onde se argumenta que a manutenção da prova na data originalmente prevista beneficiaria os alunos de escolas privadas de elite, em detrimento daqueles das escolas públicas, pois estes últimos teriam menos tempo e condições para se preparar. Há matérias que discutem tais aspectos, ressaltando o difícil acesso à internet de parcelas significativas da população, bem como o fato de as instituições privadas de educação praticamente não haverem interrompido as aulas, ministradas virtualmente - ver a respeito, dentre outros, sobre tais temas: Bergamo (2020 a); Fini (2020); Paixão (2020); Pinho (2020 a); Lopes (2020); Soprana (2020); Thompson (2020); Oliveira (2020).

Mas uma das dimensões que chamou atenção em toda essa crise foi a interferência do presidente no Ministério da Saúde, sendo que em menos de um mês três distintos ministros ocuparam a pasta. $\mathrm{O}$ último interino, é um militar, general do Exército, tendo nomeado outros 17 militares de qualificação ignorada. "É o que o humorista José Simão chamou de "Milistério"” (cf. Saúde Militarizada).

A insegurança quanto ao futuro volta a nos rondar. Há, por exemplo, intelectuais otimistas, que entendem que uma sociedade mais solidária poderá surgir (Martins, 2020), enquanto outros vaticinam que mais desigualdade e conflito deverão dar o tom (Faversani, 2020). O neurocientista Sidarta Ribeiro fala do capitalismo predatório, 
Ailton Krenak, em $O$ amanhã não está à venda, critica a "renormalização", da vida na pós-pandemia: "Tomara que não voltemos à anormalidade, pois se voltarmos, é porque não valeu nada a morte de milhares de pessoas no mundo inteiro. Depois disso tudo, as pessoas não vão querer disputar de novo o seu oxigênio com dezenas de colegas num espaço pequeno de trabalho. As mudanças já estão gestação. [...] Não podemos voltar àquele ritmo, ligar todos os carros, todas as máquinas ao mesmo tempo" (KRENAK, 2020, p. 14).

Por outro lado, Mário Sérgio Conti, transcrevendo matéria do jornal $O$ Globo (16/4/2020), diz que o "cervejeiro" Jorge Paulo Lemann, "que está amando de paixão a mortandade" provocada pela pandemia, declarou: "O que gosto mais é que toda crise é cheia de oportunidades" (CONTI, 2020). Para a elite, a doença é um detalhe. Citando Guilherme Benchimol, "o especulador classudo", Conti nos mostra a pouca inclinação de parte desse setor para qualquer forma de compromisso social: "O pico da doença já passou quando a gente analisa a classe média alta”. Em outro artigo, o colunista escreveu que o desenvolvimento tecnológico criou uma situação em que há trabalhadores demais e empregos de menos: "o trabalhador perde valor; é demitido; terceirizado; desregulamentado; precarizado. $\mathrm{O}$ empresariado não quer muita gente assalariada. Quer uma sociedade de manobristas e entregadores de pizza" (CONTI, 2020 a).

No que se refere à Covid-19, lembra que na pandemia, os políticos que representam os valores descritos no parágrafo anterior "são os de crueldade gélida e abúlica. Bolsonaro disputa com Trump a vanguarda macabra. Ele é sincero quando desconsidera a morte de milhares e pergunta: e daí? Desde que o corona não pegue a prole miliciana, tudo bem. Para ele, quem morre na peste são trastes que abrirão vagas. Por isso é aplaudido por Abílio Diniz e Joseph Safra, pelos bancos e pela Bolsa, por Edir Macedo e Silvio Santos (CONTI, 2020 a).

Paulo Guedes, operador econômico da nova ordem que aí está, apelou a prefeitos, governadores e, em especial, ao Congresso Nacional, para que não haja reajuste do salário do funcionalismo público. 
"Ele disse que se valer do momento de crise para elevar custos é fazer palanque político em cima de cadáveres" (FERNANDES, 2020). Admite que o auxílio emergencial poderia ser prolongado por mais um ou dois meses, mas que o mesmo não deveria ser superior a $\mathrm{R} \$ 200,00$, pois o benefício não poderia superar o Bolsa Família (PUPO, 2020). Em conversa com empresários, o ministro da Economia chegou a afirmar que se o valor do auxílio fosse maior, "aí ninguém trabalha. Ninguém sai de casa e o isolamento vai ser de oito anos, porque a vida está boa, está tudo tranquilo" (BOGHOSSIAN, 2020). O editorialista completa: "As declarações do ministro mostram que o governo não tem ideia de como contornar a devastação de empregos e renda causada pela crise". Guedes dá um fecho de ouro ao seu pensamento quando, na reunião de Bolsonaro com seu ministério, em 22 de abril de 2020, defende a privatização do Banco do Brasil: "É um caso pronto, e a gente não tá dando esse passo. Senhor já notou que o BNDES e a Caixa, que são nossos, públicos, a gente faz o que a gente quer. Banco do Brasil a gente não consegue fazer nada e tem um liberal lá. Então tem que vender essa porra logo". Bolsonaro responde defendendo que isso deve ser deixado para “depois de 2022” (FSP, 23/05/2020, p. A 21).

O professor Armando Alcántara Santuario, da Universidade Nacional Autônoma do México (UNAM) problematiza, em perspectiva comparada, a relação entre educação superior e a Covid-19 que, lembra, até 30 de março de 2020 havia fechado escolas e instituições de educação superior em 166 países, afetando 87\% da população estudantil, 1.520 milhões de alunos e 63 milhões de professores (ALCÁNTARA SANTUARIO, 2020, p. 76). Quase tudo foi suspenso no que se refere às viagens internacionais, programas de intercâmbio, congressos, atividades de pesquisa (p. 77). Grande parte dessas atividades foram realizadas sob a forma virtual, requerendo sistemas efetivos de gestão de aprendizagem, instalações de videoconferências e pessoal acadêmico com experiência em educação à distância (p. 76-77). A Universidade de Buenos Aires não deu aulas remotas, a principal universidade do Zimbabwe fechou as portas até novo aviso, na Malásia tudo foi sus- 
penso, na Tunísia houve boicotes dos estudantes com relação às atividades digitais. No Reino Unido, mais de 200 mil alunos assinaram petição exigindo reembolsos de seus pagamentos de matrículas, alegando que não haviam pago por educação pela internet (p. 77).

Alunos pertencentes aos grupos mais vulneráveis foram, evidentemente, os mais afetados - nos Estados Unidos, por exemplo, muitos estudantes, com o fechamento das universidades, acabam ficando sem residência, sem alimentação e sem assistência médica (p. 78). Acrescente-se a isso a crise aeroviária, o acesso reduzido à internet de parte dos discentes (em especial os que habitam as zonas rurais dos países em desenvolvimento) e as distintas situações financeiras experimentadas pelos integrantes desse segmento (p. 78).

$\mathrm{O}$ pesquisador mexicano levanta hipóteses segundo a qual, talvez "milhões de alunos abandonem por completo seus estudos ou busquem estudar em instituições mais acessíveis” (p. 79). Sugere, ainda, que as IES privadas deverão sofrer mais (pois vivem fundamentalmente da cobrança de taxas e mensalidades) que as IES públicas - estas terão que fazer mais com menos recursos (p. 79-80). E conclui escrevendo que um dos maiores desafios decorrentes da pandemia Covid-19 é reconhecer a necessidade de se "obter a equidade na educação superior para os grupos vulneráveis da sociedade” (p. 80).

Acredito que nesse período de isolamento social, a crítica mais aguda que li se encontra na coluna do jornalista Elio Gaspari que, após ouvir o médico sanitarista Gonzalo Vecina Neto, ex-diretor da Agência de Vigilância Sanitária e ex-superintendente do Hospital Sírio Libanês, escreveu que o mesmo "[...] defendeu a instituição de uma fila única para atendimento de pacientes de Covid-19 em hospitais públicos e privados. Nas suas palavras: 'Dói, mas tem que fazer. Porque se não brasileiros pobres vão morrer e brasileiros ricos vão se salvar. Não tem cabimento isso’. Acrescenta Gaspari: “a fila única não é uma ideia só dele. Foi proposta no início de abril por grupos de estudo das universidades de São Paulo e Federal do Rio” (GASPARI, 2020). 
E um homem? Não é triste um homem? Se vive há muito em solidão, Se acha que o tempo terminou, Um homem também é coisa triste.

Primo Levi, "Segunda-feira"

As palavras são metade de quem fala e metade de quem as ouve. Montaigne, Ensaios. (Livro III, p.13)

O que dizer como palavras finais nesse período de crise? Mônica Bergamo (2020 b) revela que o Instituto Ipsos realizou pesquisa, entre 7 e 10 de maio de 2020, e 68\% dos entrevistados "não desejam voltar aos seus locais de trabalho nas próximas semanas, seja por opção ou por desconforto com a ideia de sair de casa”. Com certeza, na póspandemia, vários empregos ou atividades presenciais desaparecerão ou serão drasticamente reduzidos.

Hoje é 05 de junho de 2020, primeiras horas da manhã. Brasileiros morrem às centenas diariamente, vítimas do coronavírus. $\mathrm{O}$ presidente do país praticamente ignora o que está acontecendo. Falou que era uma gripezinha, que lamentava, mas várias pessoas vão morrer mesmo, geralmente idosos, e por aí afora. Há cerca de vinte dias temos como ministro interino da Saúde um general que não dá qualquer entrevista sobre o que está acontecendo. Não são poucas as pessoas que dizem que somos governados por um idiota. Eu concordo plenamente. Isso me lembra frase célebre de Apparício Torelly (1895-1971), humorista, conhecido como Barão de Itararé, uma espécie de Karl Kraus (1874-1936) menos filosófico, mas igualmente cáustico (BELÉM, 2020): "Se há um idiota no poder, é porque os que o elegeram estão bem representados".

Mas vou além: o atual presidente, de ultra-direita, fascista e reacionário, tem pensamento governado pelo ódio. Daniel Verdú (2020) realizou excelente entrevista com o escritor italiano Antonio Scurati que, em poucas palavras, caracterizou a forma de agir dos atuais ocu- 
pantes do poder no Brasil, quando declarou: "Não espere a chegada do fascista, o soberanista já está em sua casa. Não precisam suprimir as instituições democráticas, as esvaziarão de dentro. E já está acontecendo".

O que fazer diante de um quadro desfavorável igual a esse, ao menos para aqueles que lutam por uma sociedade menos desigual? Como resistir, como tentar reverter tal situação? Enquanto cidadão, devemos nos informar pela imprensa, pelas redes sociais, ler o mais que puder e que o tempo permitir; dialogar, inclusive com quem pensa de forma distinta, procurando reafirmar nossos pontos de vista. Enquanto intelectual, docente de universidade pública há mais de quatro décadas, escrevo, falo, publico e coloco em evidência as contradições das regras que estão nos regendo - isto é, um cidadão dotado, talvez, de um poder simbólico mais efetivo. Gosto da imagem utilizada pelo escritor britânico Graham Greene (1904-1991) que, em Os farsantes (1966), sobre a ditadura de François Duvalier (Papa Doc) no Haiti, escreveu que uma caneta, assim como uma bala de prata, também consegue verter sangue. Aposto nisso.

Mas em momentos de grandes incertezas, é importante não ensarrilhar as armas da crítica, mas se deve rever certezas, reformular ideias, criar saídas sociais viáveis. Termino com bela passagem da escritora Lillian Hellman (1905-1984) que, no início de seu livro Pentimento, fala dessas idas e vindas, próprias de nosso métier como cidadão e como intelectual:

À medida que o tempo passa, a tinta velha em uma tela muitas vezes se torna transparente. Quando isso acontece, é possível ver, em alguns quadros, as linhas originais: através de um vestido de mulher surge uma árvore, uma criança dá lugar a um cachorro e um grande barco não está mais em mar aberto. Isso se chama pentimento, porque o pintor se arrependeu, mudou de ideia. Talvez se pudesse dizer que a antiga concepção, substituída por uma imagem ulterior, é uma forma de ver, e ver de novo, mais tarde. 


\section{Referências}

ALBUQUERQUE, Ana Luiza; GARCIA, Diego. Rio restringe circulação em bairros mais aglomerados. Folha de São Paulo, "Saúde coronavírus", 13/05/2020, p. B1.

ALCANTÁRA SANTUARIO, Armando. Educación superior y Covid19: una perspectiva comparada. In: IISUE. Educación y pandemia. Una visión académica. México: UNAM, p. 75-82. <http://www.iisue.unam.iisue/covid/educacion.y.pandemia $>$, consultado em: 25 maio 2020 .

ALVES, Gabriel; MACHADO, Renato. Brasil passa de mil mortes por coronavírus registrado em 24 horas. Folha de São Paulo, "Saúde Coronavírus", 20/05/2020, p. B1.

ARÊAS, Vilma. Um beijo por mês. São Paulo: Luna Parque, 2018 (2a reimp. 2019).

BARBON, Julia. Médicos do Rio continuam sem salário em meio a pandemia. Folha de São Paulo, “Saúde Coronavírus", 13/05/2020, p. B3.

BATISTA, Everton Lopes. Sobreviventes da Covid-19 podem ter de insuficiência renal a perda cognitiva. Folha de São Paulo, "Saúde Coronavírus", 18/05/2020, p. B8.

BELÉM, Euler de França. 40 frases impagáveis do Barão de Itararé. Revista Bula $<$ https://www.revistabula.com/1557-40-frases-impagaveisbarao-de-itarare/>. Consulta em: 23 maio 2020.

BERGAMO, Mônica. Taís Araújo. Basta um peteleco para seu castelo de cartas cair. Folha de São Paulo, "Coronavírus Ilustrada”, 26/04/2020, p. B 13.

. Mal necessário. Folha de São Paulo, "Coronavírus Ilustrada”, 15/05/2020 a, p. B 12. 
. Eu não. Eu não 2. Folha de São Paulo, "Coronavírus Ilustrada”, 27/05/2020 b, p. B9.

BOGHOSSIAN, Bruno. A vida boa de Guedes e Bolsonaro. Folha de São Paulo, "Opinião", 22/05/2020, p. A2.

BRAGATTO, Susana. Diário de confinamento - Nos dias que nos esperam, teremos motivos, muitos, para sofrer e desfrutar. Folha de São Paulo, “Mundo Coronavírus", 01/05/2020, p. A14.

CANCIAN, Natália; PINTO, Ana Estela de Souza. Após pressão de Bolsonaro, Ministério da Saúde amplia o uso de cloroquina. Folha de São Paulo, "Saúde e Corona”, 21/05/2020, p. B3.

CANZIAN, Fernando. Entidades médicas vão à Justiça contra uso da droga. Folha de São Paulo, "Saúde Coronavírus", 21/05/2020, p. B3.

Médicos temem ser pressionados a prescrever cloroquina. Folha de São Paulo, "Saúde Coronavírus”, 19/05/2020, p. B3.

. Pandemia aumentará a desigualdade em hora muito infeliz para o Brasil - Walter Scheidel (Entrevista). Folha de São Paulo, “Mundo Coronavírus”, 19/05/2020 a, p. A11.

CASTRO, Ruy. Talentos no confinamento. Folha de São Paulo, “Opinião", 29/05/2020, p. A2.

COLUCCI, Claudia. Einstein e Sírio Libanês fazem cortes de salários. Folha de São Paulo, "Saúde Coronavírus “, 19/05/2020, p. B5.

CONTI, Mário Sérgio. Mãos lavadas com sangue. Folha de São Paulo, "Ilustrada Coronavírus, 9/05/2020, p. B14.

. O massacre dos inocentes. Folha de São Paulo, "Ilustrada Coronavírus", 23/05/2020 a, p. B11.

DIAS, Marina; BENEVIDES, Bruno. Não quero pessoas infectando nosso povo, diz líder dos EUA \{Trump\}. Folha de São Paulo, "Coronavírus Mundo", 20/05/2020, p. A17. 
DUCROQUET, Simon; FARIA, Flávia; GARCIA, Guilherme. A cada dez dias, coronavírus chega a mais de 630 municípios. Folha de São Paulo, "Saúde Coronavírus", 22/05/2020, p. B3.

FAVERSANI, Fábio. Mais desigualdade e conflito. Folha de São Paulo, “Tendências e Debates - Opinião", 25/04/2020, p. A3.

FELINTO, Marilene. Hospital de luxo é um sonho de consumo diante do colapso da rede pública nacional. Folha de São Paulo, "Coronavírus Opinião", 24/05/2020, p. B9.

FERNANDES, Talita. Dar reajuste é usar cadáver como palanque, diz Guedes. Folha de São Paulo, "Mercado Coronavírus”, 16/05/2020, p. A20.

FINI, Maria Inês. A escola faz falta para todos. Folha de São Paulo, “Tendências e Debates - Opinião”, 16/05/2020, p. A3.

GARCIA, Diego; PUPO, Reginaldo; TRINDADE, Luciano. Litoral de SP tenta conter invasão em Feriadão. Folha de São Paulo, "Saúde Coronavírus", 20/05/2020, p. B3.

GASPARI, Elio. A fila única para a Covid-19 está na mesa. Folha de São Paulo, "Poder Coronavírus", 03/05/2020, p. A10.

GRAMSCI, Antonio. Sobre o conceito de previsão ou perspectiva. Cadernos do cárcere, vol. 3, Rio de Janeiro: Civilização Brasileira, 2007.

HELMAN, Lillian. Pentimento. Rio de Janeiro: Francisco Alves, 1980.

JUNG, Nádia. Quarentena causada pelo vírus bagunça e piora o sono. Folha de São Paulo, "Coronavírus Saúde, 26/04/2020, p. B7.

KRENAK, Ailton. O amanhã não está à venda. São Paulo: Companhia das Letras, 2020.

LEAL, Cláudio. Vidas em quarentena. Folha de São Paulo, "Ilustríssima”, 07/06/2020, p. B12.

LEMOS, Amanda. Lotado, vôo BH-SP tem desrespeito a regras de distância. Folha de São Paulo, 17/05/2020, p. A23. 
LOPES, Alexandre. Entre a peste e a pandemia. Folha de São Paulo, “Tendências e Debates - Opinião”, 16/05/2020, p. A3.

MAISONNAVE, Fabiano. Estamos em uma guerra, e na guerra você enterra - Entrevista: Arthur Virgílio Neto. Folha de São Paulo, "Saúde Coronavírus", 13/05/2020, p. B3.

MARTINS, Paulo. Entre a peste e a pandemia. Folha de São Paulo, “Tendências e Debates - Opinião”, 25/04/2020, P. A3.

MATTOS, Laura. Quarentena trouxe lições para a educação que depois não deveriam cair no limbo. Folha de São Paulo, "Cotidiano", 15/05/2020, p. B16.

MONTAIGNE, Michael de. Ensaios (trad. Rosemary Costhek Abílio). São Paulo: Martins Fontes, 2001 (Livro III).

MUNIZ, Sérgio. En San Antonio y São Paulo...(A paciente construção ou Timbiriche, Tocayo y Marabu). São Paulo: Oficina de Textos, 1997.

NOVA rotina no icônico edifício Copan retrata o desafio de viver na pandemia. Folha de São Paulo, "Mercado Coronavírus", 31/05/2020, p. A20.

OLIVEIRA, Joana. Em meio à rotina de aulas remotas, professores reclamam ansiedade e sobrecarga de trabalho. El País. $<$ www.brasil.elpais.com/brasil/2020-05-21/em-meio-a-rotina-de-aulas-remotas-professores-relatam-ansiedade-e-sobrecarga-de-trabalho.html/\#?

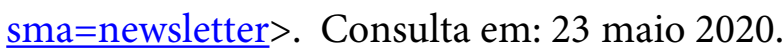

PAIXÃO, André. Só 6 das 69 universidades federais adotaram ensino à distância após a paralisação por causa da Covid-19. O Globo, 14/05/2020, p.7.

PASSOS, Paulo. 'Não tire sua máscara' substitui o 'aperte o cinto' (Depoimento). Folha de São Paulo, "Saúde Coronavírus", 17/05/2020, p. A23.

PINHO, Flávia G. Só 47\% dos alunos da rede estadual de SP assistem aula. Folha de São Paulo, "Saúde Coronavírus", 14/5/2020 a, p. B1. 
. Flávia G. Confinados, moradores se cansam da própria casa e procuram reformas. Folha de São Paulo, "Sobremorar Coronavírus", 02/05/2020, p. B17.

PINASSI, Maria Orlanda. Eu e a pandemia - impressões da quarentena. <https://correiodacidadania.com.br> , consultado em: 26 abr. 2020. PINTO, Ana Estela de Souza. Passageiro de avião terá que pedir para ir ao banheiro. Folha de São Paulo, "Coronavírus Mercado", 17/05/2020, p. A23.

PITOMBO, João Pedro. Entrevistadores do Ibope que coletaram testes de Covid-19 se contaminaram. Folha de São Paulo, "Saúde Coronavírus", 20/05/2020, p. B4.

PORTO, Walter. Fechamento dos cinemas, sem previsão de reabertura. Folha de São Paulo, "Ilustrada", 24/04/2020, p. B10.

PUPO, Fábio. Guedes admite dar auxílio emergencial por mais 1 ou 2 meses, mas de R \$200,00. Folha de São Paulo, "Mercado Coronavírus", 21/05/2020, p. A13.

RIBEIRO, Sidarta. Navegação de capotagem. Folha de São Paulo, "Ilustríssima Coronavírus", 17/05/2020, p. B14.

RODRIGUES, Artur; ALMEIDA, Lalo de; GOULART, Mariana. Para profissionais da saúde no Pacaembu, 'a guerra chegou'. Folha de São Paulo, “Saúde Coronavírus”, 13/05/2020, p. B6.

SALDAÑA, Paulo; COLETTA, Ricardo Della. Governo federal entrega só $6 \%$ dos respiradores. Folha de São Paulo, "Saúde Coronavírus", 19/05/2020, p. B4.

SANT’ANNA, Emílio. 2 meses após a $1^{\text {a }}$ morte por Covid-19, Brasil é cenário de pesadelos. Folha de São Paulo, "Saúde Coronavírus", 16/05/2020, p. B6.

SAÚDE militarizada. Folha de São Paulo, "Editoriais - Opinião", 21/05/2020, p. A2. 
SEVERINO, Eleonora; SEVERINO, Ariel. Casal conta como é sua rotina após dois meses sem pisar nas ruas (Depoimento). Folha de São Paulo, "Saúde Coronavírus", 17/5/2020, p. B6.

SOPRANA, Paula. Cerca de 70 milhões têm acesso precário à internet na pandemia. Folha de São Paulo, "Mercado Coronavírus", 17/05/2020, p. A19.

'TEM que vender essa porra logo', diz Guedes sobre o Banco do Brasil. Folha de São Paulo, "Mercado", 23/05/2020, p. A21.

THOMPSON, Miguel. Pandemia amplia abismo entre escolas públicas e privadas. Folha de São Paulo, "Vestibular no meio do ano", 31/05/2020, p. 5.

VERDÚ, Daniel. Antonio Scurati: Ridicularizamos Trump por seu físico e Salvini por ser vulgar, e assim ganham eleitores que pensam que imbecis somos nós“ (Entrevista). <https://brasil.elpais.com/brasil/ 2019/12/30/eps/157770 5627_59 3341.html >. Acesso em: 23 maio 2020. 